\section{Percentage of Dry Matter and Oil Content Are Not Reliable Indicators of Fruit Maturity or Quality in Late-harvested 'Hass' Avocado}

\author{
Peter J. Hofman
}

Maroochy Research Station, Queensland Horticulture Institute, Department of Primary Industries, P.O. Box 5083 SCMC, Nambour, 4560, Australia

Marcelle Jobin-Décor

Queensland Agricultural Biotechnology Centre, Queensland Horticulture Institute, Department of Primary Industries, University of Queensland, St Lucia, 4072, Australia

\section{Janet Giles}

Biometry Group, Queensland Horticulture Institute, Department of Primary Industries, Locked Mail Bag 4, Moorooka, Qld 4105, Australia

Additional index words. Persea americana, maturity, quality

\begin{abstract}
The potential to use percentage of dry matter (DM) and/or oil of the flesh of 'Hass' avocado as a maturity standard to determine the latest harvest for acceptable fruit quality, was investigated. 'Hass' avocado fruit were harvested from early October to mid-January from a commercial orchard in subtropical Queensland. The percentage of DM and oil changed little during the harvest period, and the eating quality of the flesh remained high. However, the incidence of body rots (caused mainly by Colletotrichum sp.) and the flesh disorders grey pulp and vascular browning, increased with harvest. These results indicate that percentage of DM and oil are not reliable late-maturity standards because of the inconsistent change with later harvests, and that disease and internal disorders can be the main determinants of latest acceptable harvest, rather than eating quality.
\end{abstract}

In cooler production regions, there is often commercial advantage in delaying the harvest of late-season avocado (Persea americana Mill.) fruit in order to access higher-priced markets, when fruit supply is low. However, higher disease and internal disorder severity and lower eating quality may occur in later harvested fruit (Erickson et al., 1970). Considerable research has focused on reliable indices to determine early maturity standards for avocado, but little has been published on a latematurity standard to ensure acceptable quality of late-harvested 'Hass' avocado.

To test the feasibility of using the percentage of dry matter (DM) and oil of the flesh (percentage oil) as indicators of the ripe fruit quality of late-harvested avocado, 'Hass' fruit were harvested from the same orchard block of 18- to 20-year-old trees as described previously (Hofman and Jobin-Décor, 1999). Four, average-size fruit per tree from the south side of each of 10 trees were harvested at $\approx 3$-week intervals from 9 Oct. 1996 to 22 Jan. 1997.

Received for publication 9 Mar. 1999. Accepted for publication 26 Aug. 1999. We thank the Australian Avocado Growers Federation, the Horticulture Research and Development Corp. and the Dept. of Primary Industries, Queensland, for financial support. The cost of publishing this paper was defrayed in part by the payment of page charges. Under postal regulations, this paper therefore must be hereby marked advertisement solely to indicate this fact. of 'Hass' avocado fruit. ${ }^{v}$ Mean separation within columns by protected LSD, $P \leq 0.05$.

${ }^{\text {uStandard deviation. }}$ disorders and body rots (caused mainly by Colletotrichum sp.) was recorded.

For each harvest of each tree, sample flesh from fruit was pooled, a subsample presented to a panel of at least 12 experienced tasters, and the eating quality rated on an hedonic scale of $1=$ dislike extremely, $5=$ neither like nor dislike, to $9=$ like extremely. Another subsample was weighed, dried at $65^{\circ} \mathrm{C}$ to constant weight, and the percentage of DM at harvest calculated (Hofman and Jobin-Décor, 1999).

The oil content of fruit from five trees was measured using soxhlet extraction with petroleum ether $\left(40^{\circ}\right.$ to $\left.60^{\circ}\right)$ for $16 \mathrm{~h}$ (Lewis et al., 1978). Flesh samples were dried to constant weight at $65{ }^{\circ} \mathrm{C}$ before extraction, and the results expressed on a dry weight basis.

The percentage of flesh DM declined slightly between early October and late January, and the percentage of oil showed no consistent change (Table 1). Flesh eating quality fluctuated mainly between 7 (like moderately) and 8 (like very much). There was no consistent effect of harvest date on DTR (average of $12.9 \mathrm{~d}$ ).

Most research has shown that the percentage of DM and oil of avocado flesh increases, and the DTR decreases, with harvest date (Ranney, 1991), especially at early maturity. This was not observed in the current study in later harvests, and Hofman et al. (1998) also noted that DTR and the percentage of DM can remain static or can decrease from the middle to late commercial harvest period, depending on the area of production and season.

'Hass' fruit eating quality from subtropical southeastern Queensland is generally considered to decrease when harvested later than about mid-December and to be unacceptable by mid-January. However, in this investigation, eating quality remained high and varied little with harvest. Erickson et al. (1970) found off-flavors in late-harvested avocado fruit from several, but not all, regions sampled (California); that lower eating quality was not always related to higher oil content; and that there appeared to be seasonal and location effects on the interaction between these parameters. This may explain the differences between the current results and commercial observations.

The percentage of the skin area that was black at harvest, and the percentage of the ripe

Table 1. Effects of time of harvest during the late commercial harvest period (subtropics) on characteristics

\begin{tabular}{|c|c|c|c|c|c|c|c|}
\hline \multirow{2}{*}{$\begin{array}{l}\text { Harvest } \\
\text { date }\end{array}$} & \multirow{2}{*}{$\begin{array}{c}\text { Dry matter } \\
(\%)^{\mathrm{z}}\end{array}$} & \multirow{2}{*}{$\begin{array}{c}\text { Flesh oil } \\
(\%)\end{array}$} & \multirow{2}{*}{$\begin{array}{c}\text { Eating } \\
\text { quality }^{\mathrm{y}}\end{array}$} & \multicolumn{4}{|c|}{ Skin color } \\
\hline & & & & $\%$ Black $^{\mathrm{x}}$ & $\%$ Green $^{x}$ & $\mathrm{~L}$ value & $\overline{h^{\circ} w}$ \\
\hline 9 Oct. & 31.4 & $61.6 \mathrm{a}^{\mathrm{v}}$ & $7.4 \mathrm{bc}$ & $13.2(5) \mathrm{a}$ & $0(0) \mathrm{a}$ & $26.6 \mathrm{a}$ & 39.0 \\
\hline 29 Oct. & 31.1 & $65.8 \mathrm{a}$ & $7.4 \mathrm{c}$ & $27.7(22) b$ & $0(0) \mathrm{a}$ & $26.4 \mathrm{a}$ & 40.9 \\
\hline 20 Nov. & 30.8 & $61.2 \mathrm{a}$ & $7.2 \mathrm{ab}$ & $51.9(62) \mathrm{c}$ & $22.5(15) b c$ & $28.3 \mathrm{c}$ & 50.5 \\
\hline 11 Dec. & 29.9 & $68.6 \mathrm{a}$ & $7.0 \mathrm{a}$ & $49.5(58) \mathrm{c}$ & $31.5(27) \mathrm{c}$ & $27.3 \mathrm{~b}$ & 47.3 \\
\hline 1 Jan. & 30.7 & $61.2 \mathrm{a}$ & $7.5 \mathrm{c}$ & & $15.0(7) b$ & $27.0 \mathrm{ab}$ & 40.5 \\
\hline 22 Jan. & 28.8 & & $7.3 \mathrm{bc}$ & & & & 40.6 \\
\hline $\mathrm{SD}^{\mathrm{u}}$ & 1.3 & 5.7 & 0.3 & 18.7 & 16.5 & 1.5 & 20.5 \\
\hline
\end{tabular}

z31.7 - 0.02 (harvest date, expressed as days since 30 Sept.), $R^{2}=29 \%, P \leq 0.001$

${ }^{y} 1=$ dislike extremely; $5=$ neither like nor dislike; $9=$ like extremely.

${ }^{x}$ Data were angular transformed before analysis. Backtransformed means are given in parentheses.

w32.8 + 0.553 (harvest date, expressed as days since 30 Sept.) -0.005 (harvest date) $)^{2}, R^{2}=4 \%, P \leq 0.05$. 


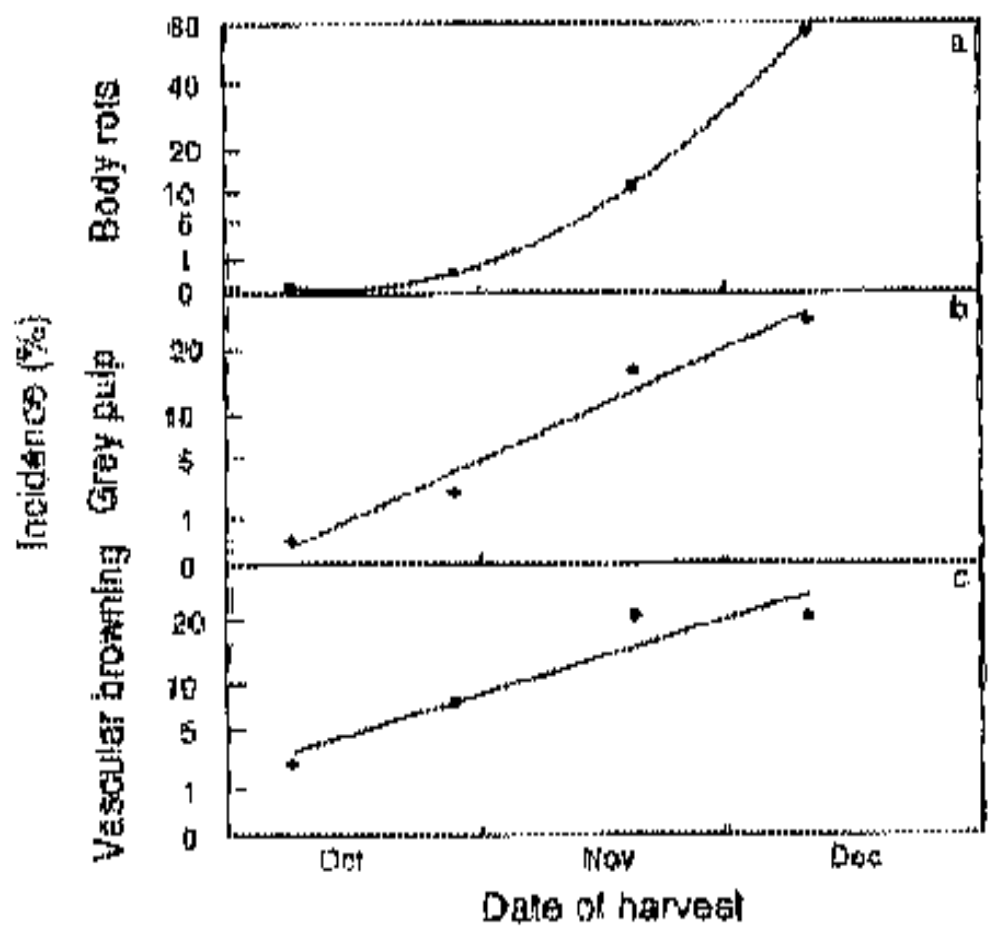

Fig. 1. Effect of harvest date on the incidence (percentage of fruit affected) of body rots (a), grey pulp (b) and vascular browning (c) in ripe 'Hass' avocado fruit. Data were angular transformed. The regression equations are angular (body rots) (degrees) $=2.8-0.436$ (harvest date) +0.0151 (harvest date) $)^{2}, R^{2}=79 \%$ $(P \leq 0.001)$; angular (grey pulp) (degrees) $=-1.9+0.456$ (harvest date), $R^{2}=38 \%(P \leq 0.001)$ and angular (vascular browning) $($ degrees $)=7.6+0.306$ (harvest date),$R^{2}=17 \%(P \leq 0.05)$.

fruit with $>10 \%$ green skin, increased from harvest 1 to 3 and 4 , respectively (Table 1 ). The change in skin color of ripe fruit was confirmed by the higher $\mathrm{L}$ (less black) and $\mathrm{h}^{\circ}$ (more yellow) of the skin during the middle harvests.

The incidence of body rots, grey pulp, and vascular browning increased with harvest date (Fig. 1). This has also been observed by other researchers (Thorp et al., 1997), and suggests that disease and internal disorders need to be considered, along with eating quality, as deter-

For percentage of DM and oil to be reliable indicators of late-harvested fruit quality, they would have to change consistently with harvest date, and do this consistently over a range of seasons and locations. If this is not the case, even in only one season or one location, they are not reliable indicators. On this basis, our minants of quality in late-harvested fruits. results indicate that these parameters are not reliable estimates of late-harvest maturity and acceptable ripe fruit quality, since they did not change as harvest was delayed, while disease and disorder incidence increased during the same period.

Perhaps a latest acceptable harvest date, which is determined by production location and season, may be more suitable. For example, Erickson et al. (1970) suggested that monitoring over several seasons may indicate an approximate harvest time when the risk of off-flavors increased, and this could also be relevant in predicting the increasing risk of disease and internal disorders with later harvests.

\section{Literature Cited}

Erickson, L.C., I.L. Eaks, and G.G. Porter. 1970. Over-maturity in 'Hass' avocados. California Avocado Soc. Yrbk. 54:62-65.

Hofman, P.J. and M. Jobin-Décor. 1999. Effect of fruit sampling and handling procedures on the percentage dry matter, fruit mass, ripening and skin color of 'Hass' avocado. J. Hort. Sci. Biotech. 74:277-282.

Hofman, P.J., S. Vuthapanich, A. Klieber, A.W. Whiley, and D.H. Simons. 1998. Effect of locality, irrigation and paclobutrazol on quality of 'Hass' avocado, p. 67-76. In: L.M. Coates, P.J. Hofman, and G.I. Johnson (eds.). Disease control and storage life extension in fruit, Chiang Mai, Thailand, May 1997. Australian Centre for Intl. Agr. Res., Canberra.

Lewis, C.E., R. Morris, and K. O’Brien. 1978. The oil content of avocado mesocarp. J. Sci. Food Agr. 29:943-949.

Ranney, C. 1991. Relationship between physiological maturity and percent dry matter of avocados. California Avocado Soc. Yrbk. 75:71-85.

Thorp, T.G., D. Hutching, T. Lowe, and K.B. Marsh. 1997. Survey of fruit mineral concentrations and postharvest quality of New Zealand-grown 'Hass' avocado (Persea americana Mill.). N.Z. J. Crop Hort. Sci. 25:251-60. 